\title{
Health Insurance Reform: The impact of a Medicare Buy-In
}

\author{
Gary D Hansen * \\ Minchung $\mathrm{Hsu}^{\dagger}$ \\ Junsang Lee \\ UCLA \\ GRIPS \\ SKKU
}

March 25, 2014

\begin{abstract}
The steady state general equilibrium and welfare consequences of a Medicare buyin program, optional for those aged 55-64, is evaluated in a calibrated life-cycle economy with incomplete markets. Incomplete markets and adverse selection create a potential welfare improving role for health insurance reform. We find that adverse selection eliminates any market for a Medicare buy-in if it is offered as an unsubsidized option to individual private health insurance. The subsidy needed to bring the number of uninsured to less than 5 percent of the target population could be financed by an increase in the labor income tax rate of just 0.03 to 0.18 percent depending on how the program is implemented.
\end{abstract}

\footnotetext{
*University of California, Los Angeles. Email: ghansen@econ.ucla.edu.

†National Graduate Institute for Policy Studies, Tokyo. Email: minchunghsu@grips.ac.jp.

†Sungkyunkwan University, Seoul. Email: junsanglee@skku.edu.

${ }^{\S}$ This project has benefited from research support provided by GRIPS where much of this research was completed while Hansen and Lee were Visiting Scholars.
} 


\section{Introduction}

A primary goal of health care reform in the United States is to provide group health insurance to individuals who do not have access to this through their employers. In this way, relatively expensive patients with preexisting health conditions are pooled with healthy individuals who rarely see a doctor so that health care is provided to everyone at an affordable price independent of health status. A free market, however, has difficulty providing this kind of insurance due to adverse selection. That is, healthy individuals can obtain even less expensive insurance by seeking out coverage that is priced according to this individual's own health status. As a result, the market for group insurance unravels and no equilibrium price exists.

The framework introduced by the "Patient Protection and Affordable Care Act" (ACA) signed by President Obama in March 2010, is designed to achieve this goal through a combination of features that include penalties associated with not purchasing insurance (an insurance mandate), income based subsidies, and restrictions on the type of insurance contracts that can be written. Much of the complexity of this reform comes from the fact that it provides a mechanism for overcoming the adverse selection problem and increasing access to group insurance using private insurance companies. This paper considers a much simpler approach that was considered at the time the ACA was being debated and has the feature that participation is entirely voluntary and would offer group insurance through a public option that would compete with other types of insurance plans. This policy allows individuals who are between 55 and 64 to have the option of enrolling in Medicare-a Medicare buy-in program. ${ }^{1}$

In his State of the Union address in each of the last three years of his presidency, Bill Clinton proposed allowing individuals of age 62 through 64 buy into this program. Later, in December 2009, the possibility of an optional Medicare buy-in was debated in congress as an alternative to the ACA [see Hitt and Adamy (2009)]. This is perhaps not surprising given that polls conducted in 2000, 2004 and 2009 by the Kaiser Family Foundation indicate that about three-quarters of adults in the U.S. support the idea of allowing a Medicare buy-in for those of age 55-64. In addition, this proposal targets a population of individuals who are more likely to be unhealthy. Again according to the Kaiser Family Foundation, in 2008 only 13 percent of the individuals 55-64 are uninsured, but 26 percent of those uninsured are unhealthy. In contrast, 28 percent of individuals 19-34 are uninsured, but only of 7 percent of these uninsured are unhealthy [see Jacobson, Schwartz and Neuman (2009)].

\footnotetext{
${ }^{1}$ See Jacobson, Schwartz and Neuman (2009) and Smolka and Thomas (2009) for discussion of the specific proposals put forward.
} 
Even in the post ACA era, a Medicare buy-in continues to be debated. In April 2013, The National Commission on Fiscal Responsibility and Reform, chaired by Erskine Bowles and Alan Simpson, have proposed increasing the eligibility age for Medicare to 67, but allow people to buy into Medicare at age $65 .^{2}$

Given that the this paper is being written prior to the actual implementation of the ACA, we evaluate the general equilibrium and welfare consequences of this policy reform from the perspective of a benchmark calibrated to the pre-ACA economy. The existing Medicare program for individuals ages 65 and over is heavily subsidized by the government. A key question addressed in this paper is how much subsidy is required to overcome the adverse selection problem and to induce most of the currently uninsured in the 55-64 age bracket to voluntarily purchase this coverage.

This policy analysis is carried out using a calibrated life-cycle economy with incomplete markets and endogenous labor supply. In our model, working age individuals face idiosyncratic productivity shocks, choose whether or not to work (labor is indivisible), accumulate claims to capital, and can purchase private health insurance if they do not receive group health insurance through their employer. They face uncertainty each period about their future health status, medical expenditures and the length of their life. Retired individuals receive social security and Medicare which, along with accumulated savings, is used to finance consumption and medical expenditures. Individuals who retire early, between age 55 and 64, might be offered group retiree health insurance.

In this environment, incomplete markets and adverse selection, which restricts the type of insurance contracts available in equilibrium, creates a potential role for health insurance reform. However, the price of such a program, if it is to be self-financing, depends crucially on who chooses to enroll. Relatively healthy individuals may prefer individual health insurance or self-insurance and their exit from the pool would raise the cost of the buy-in program for those who remain. In fact, in our calibrated economy, this adverse selection problem eliminates any market for a self-financing Medicare buy-in program.

Hence, if this voluntary program is to have any impact, it must be partially subsidized by the government to make it more attractive to healthy individuals. We therefore compare our benchmark economy, in which there is only individual health insurance or employer provided group insurance for those under age 65, with economies with a Medicare buy-in program that is subsidized at various rates by the government.

We find that by subsidizing the buy-in program, it is possible to bring the number of

\footnotetext{
${ }^{2}$ See Bowles and Simpson (2013). In addition, Berenson, Holahan and Zuckerman (2013) from the Urban Institute make a similar proposal.
} 
individuals aged 55-64 without insurance to below 5 percent without incurring large tax increases to finance the program. In particular, a 30 percent subsidy brings the fraction uninsured down from 30 percent in the benchmark to 4.5 percent. Due to the general equilibrium effects of introducing this policy, total labor taxes only need to be increased by 0.18 percentage points above the tax rate for the benchmark economy. In addition, while lifetime utility is somewhat lower for an individual born in this economy compared with that of an individual born in the benchmark economy, those of age 36 or higher enjoy greater lifetime utility on average from their current age forward.

We also consider an experiment in which the subsidized Medicare buy-in program is accompanied by the elimination of group insurance provided by employers for those who qualify for the buy-in program. It turns out that the subsidy implicitly provided by the tax deductability of employer provided insurance is greater than the subsidy offered by the Medicare buy-in program and, hence, tax rates are lower when it is eliminated in favor of the buy-in. This implies that this economy is associated with higher steady state welfare than the benchmark economy.

Our paper contributes to the literature pioneered by Auerbach and Kotlikoff (1987) using calibrated general equilibrium life cycle models to study dynamic fiscal policy and social programs such as social security. It also builds on the the quantitative literature using dynamic general equilibrium models with incomplete markets pioneered by Aiyagari (1994), Huggett (1993) and Imrohoroglu (1989). While this literature has grown to be quite large, there are relatively few papers that have applied this approach to the study of health insurance programs.

Three exceptions are Attanasio, Kitao and Violante (2010), Jeske and Kitao (2009) and Pashchenko and Porapakkarm (2013). The first of these uses a model similar to ours to evaluate alternative funding schemes for Medicare given demographic projections for the next 75 years. Jeske and Kitao (2009) study the role of adverse selection in a model where individuals choose whether to or not to purchase health insurance, which is either group insurance, provided through employers, or individual insurance. The paper argues that a regressive tax policy that subsidizes insurance for those receiving it through their employers by making premiums tax deductible is welfare improving since it encourages healthy individuals to stay in the program rather than seek private insurance. That is, the tax policy serves a role similar to the subsidizing the Medicare buy-in in our model. Pashchenko and Porapakkarm (2013) use a model similar to ours to evaluate the positive and normative consequences of the 2010 Affordable Care Act.

The remainder of the paper is organized as follows. We describe the theoretical model 
in section 2 and the model calibration in section 3. Results are presented in section 4, and concluding comments are given in section 5 .

\section{Model}

We use a general equilibrium life-cycle model with endogenous demand for private health insurance, endogenous labor supply and incomplete markets for our analysis of health insurance reform. There is uncertainty resulting from idiosyncratic productivity shocks, whether one has access to employer provided group insurance, health status, medical expenditure shocks, and the length of life.

\subsection{Demographics}

The economy is populated by overlapping generations of individuals of age $j=1,2, \ldots, J$. An individual of age $j$ survives until next period with probability $\rho_{j, h^{\prime}}$ which depends on age $j$ and health status $h^{\prime} \in\left\{h_{g}, h_{b}\right\}$. If an individual reaches the maximum age $J, \rho_{J, h^{\prime}}=0$ for any $h^{\prime}$. There is no population growth.

\subsection{Financial Market Structure}

Individuals can hold non-state contingent assets which are claims to capital used in production. In particular, beginning of period asset holdings of a given individual of age $j$ are denoted by $a_{j}$. We assume that $a_{0}=0$. In addition, all individuals receive a lump sum transfer, $b$, which is unintended bequests from individuals that did not survive from the previous period. The rate of return on asset holdings is denoted by $r$, which is equal to the marginal product of capital minus the rate of depreciation in equilibrium. These assets can be used by households to partially insure themselves against any combination of idiosyncratic labor productivity shocks and medical expenditure shocks.

The choice of next period asset holdings is subject to a borrowing constraint, $a^{\prime} \geq 0$. This, along with an assumption of no annuity markets, is the source of market incompleteness in our model. The borrowing limit especially impacts the asset holding decision of low-wealth households since they cannot smooth their consumption over time when they are hit by negative shocks to their disposable income. 


\subsection{Preferences and the Labor Decision}

Each period, individuals are endowed with one unit of time that can be allocated to market work and leisure. If they choose to spend $n$ hours on the market work, their earnings are given by $(w z n)$, where $w$ is the market wage per effective unit of labor, and $z$ is an idiosyncratic labor productivity shock that is revealed at the beginning of the period.

The labor decision is indivisible. That is, the choice of $n$ is restricted as follows: $n \in$ $\{0, \bar{n}\}$ if $j<J^{r} ; n=0$ if $j \geq J^{r}$, where $J^{r}$ is the age of mandatory retirement. Individuals choose consumption and hours worked to maximize utility, which is given by

$$
E\left[\sum_{j=1}^{J} \beta^{j-1}\left(\prod_{t=1}^{j-1} \rho_{t, h}\right) u\left(c_{j}, n_{j}\right)\right],
$$

Here, $0<\beta<1$ is the subjective discount factor and $u(c, n)$ is the period utility function, the functional form for which was chosen to be compatible with balance growth:

$$
u(c, 1-n)=\frac{\left[c^{\phi}(1-n)^{1-\phi}\right]^{1-\mu}-1}{1-\mu} ;
$$

where $\phi$ determines the relative preference for consumption versus leisure, and $\mu$ governs the both the intertemporal elasticity of substitution for consumption and the labor supply elasticity. The coefficient of relative risk aversion is given by $\gamma=1-\phi+\phi \mu{ }^{3}$

\subsection{Health, Medical Expenditure and Health Insurance}

\subsubsection{Heath status and medical expenditure uncertainty}

Given their beginning of period health status $h$ determined in the previous period, individuals face exogenous uncertainty about their current health status $h^{\prime}$ and resulting medical expenditure $x .{ }^{4}$ Health status evolves according to a two-state Markov chain where $h \in\left\{h_{g}, h_{b}\right\}$, denoting good and bad health. The transition matrix, $\pi_{j}^{h}\left(h^{\prime}, h\right)$, depends on age.

\footnotetext{
${ }^{3}$ See Heathcote, Storesletten and Violante (2008) for details. A separable utility between consumption and leisure is often used in the related literature, but this form is consistent with balanced growth only when $\mu$ is one:

$$
u(c, 1-n)=\frac{c^{1-\mu}-1}{1-\mu}-\psi \frac{n^{1+1 / \varepsilon}}{1+1 / \varepsilon}
$$

where $\psi$ is a disutility parameter and $\varepsilon$ is Frisch elasticity of labor supply.

${ }^{4}$ We say that the uncertainty is exogenous because there is no sense in which actions taken by individuals can affect their health status. This assumption eliminates moral hazard from our model economy.
} 
The probability distribution of the idiosyncratic medical expenditure shock $x$ depends on age and current health status, $h^{\prime}$. We assume that $h^{\prime}$ and $x$ are revealed after the health insurance decision has been made. In particular, $x$ is drawn from the conditional distribution $\pi_{j}^{x}\left(x \mid h^{\prime}\right)$, where $x \in X_{j, h^{\prime}}=\left\{x_{j, h^{\prime}}^{1}, x_{j, h^{\prime}}^{2}, \ldots, x_{j, h^{\prime}}^{m}\right\}$. Hence, the probability of an individual of age $j$ with beginning of period health status $h$ having expenditure equal to $x$ (and beginning of next period health status $\left.h^{\prime}\right)$ is given by $\pi_{j}^{x}\left(x \mid h^{\prime}\right) \pi_{j}^{h}\left(h^{\prime}, h\right)$.

\subsubsection{Group health insurance for employees and retirees (EHI and RHI) and indi- vidual health insurance (IHI)}

Individuals can partially insure medical expenditure uncertainty with health insurance that covers a fraction $\omega$ of realized medical expenditures $x$.

To characterize the current US health insurance market, three types of insurance are incorporated in the model - employment-based group health insurance (EHI), group health insurance for early retirees (RHI), and individual (private) health insurance (IHI). The group insurance options, which are offered by employers, are required by law not to discriminate based on health status. In the latter, insurance companies are permitted to price-discriminate based on individual characteristics.

We assume that everyone has access to IHI, but EHI and RHI are available only if offered by the employer, and RHI is only available to early retirees, individuals aged $J^{g}$ to $J^{r}-1$, which will correspond to ages 55-64 in our quantitative analysis. That is, $J^{g}$ is the age at which an individual qualifies for RHI (if offered) and $J^{r}$ is the age at which an individual must retire. At this point, an individual qualifies for Medicare, which is described in the next subsection. If an individual chooses not to work prior to age $J^{g}$, there is no possibility of having coverage through group insurance. The premium charged for EHI, $q^{e}$, does not depend on an individual's age or health status. If EHI is offered, the premium is paid by the employer but the amount will be subtracted from an employee's pre-tax wage income to ensure that total compensation is consistent with labor market equilibrium. An offer of EHI comes with the job offer (the revelation of the idiosyncratic productivity shock) at the beginning of a period when agents make their labor supply decisions. We denote whether or not an individual has an EHI offer by the state variable $e$, where $e \in\{0,1\}$. Whether or not the individual actually accepts the EHI offer is denoted by an indicator $\imath_{E H I}$, where $\imath_{E H I}=1$ if $e=1$ and $n=\bar{n} ; \imath_{E H I}=0$ otherwise.

Once an individual reaches age $J^{g}$, he/she will be offered RHI if $e=1$ and $n=0$. That is, to have retiree health insurance, one must have been offered a job with EHI, but then choose not to work. In this case, if the insurance is accepted, we set $l_{R H I}=1$ and the individual gets 
charged an insurance premium equal to $q^{g}$. This form of insurance is particularly desirable for individuals in the model because it is subsidized; a fraction $\sigma_{g}$ of the total cost of the insurance is paid by the firm and $1-\sigma_{g}$ by the individual. Once the individual reaches age $J^{r}$, he/she is eligible for Medicare, which is the only health insurance offered in our model to those of age $J^{r}$ and over.

If an agent decides to buy IHI to insure medical expenditures, a premium $q^{i}(j, h)$, which depends on the individual's current age and health status, needs to be paid at the beginning of the period before the medical expenditure shock is realized. This reflects standard risk rating in the IHI market. In addition, we denote whether or not the individual has an IHI insurance contract by $\imath_{I H I}$, where $\imath_{I H I}=1$ if the individual has IHI and $\imath_{I H I}=0$ otherwise. Finally, because IHI requires that individuals be screened to determine how much they should be charged for insurance, there are additional underwriting costs that are not incurred by an insurance provider that employs some form of community rating. Our way of modeling this follows Jeske and Kitao (2009) by assuming that an IHI provider charges a markup of $\psi>1$ on the premium that would be charged in equilibrium if there were no underwriting costs.

\subsubsection{Stochastic process for $z$ and $e$}

We assume that $z$, which is idiosyncratic productivity, can take on one of $N$ possible values. In addition, we assume that the probability that EHI is offered $(e=1)$ is a function of the realized value of $z$. We also assume that the probability of a particular $(z, e)$ draw depends on health status and age. Therefore, we assume that the vector $(z, e)$ follows a Markov chain with a $(2 N) X(2 N)$ transition matrix $P^{g, j}$ for individuals of age $j$ with good beginning of period health status $\left(h=h_{g}\right)$ and a transition matrix $P^{b, j}$ for individuals with $h=h_{b}$.

\subsection{Government and Social Programs}

\subsubsection{Medicare}

Medicare is a public program sponsored by the government that provides health insurance for the elderly. Once individuals reach the eligibility age of $J^{r}$ (which corresponds to age 65), they are covered by Medicare automatically. Medicare covers a fraction $\omega_{m}$ of realized medical expenditure $x$. In addition, the government pays a fraction $\sigma_{m}$ of the total premium required to offer Medicare in equilibrium, leaving participants to pay a fraction $1-\sigma_{m}$ of the premium. 
The program is financed by a combination of contributions from the general government budget and the Medicare premium charged to benefit recipients, $q^{m}$.

\subsubsection{Social security}

The social security program provides the elderly with a benefit $S$ when they reach the eligibility age of $J^{r}$ and retire. This program is also financed by the general government budget.

\subsubsection{Minimum consumption guarantee}

In addition to Medicare and social security, the government provides means-tested social insurance in this economy. The government guarantees a minimum level of consumption $\underline{\mathrm{c}}$ by supplementing income by an amount $T$ in case the household's disposable income plus assets (net after medical expenditures) falls below $\underline{\mathrm{c}}$. That is, we employ the simple transfer rule proposed by Hubbard et al. (1995). This plays the same role in our model economy as transfer programs such as Medicaid, food stamps, and Supplemental Security Income do in the U.S.

\subsubsection{Government budget}

Government revenue consists of revenue from a labor income tax $\tau_{l}$, capital income tax $\tau_{k}$, and a consumption tax $\tau_{c}$. Additional funds are obtained from the Medicare premium, $q^{m}$. The government uses its revenue to finance all public programs and its own consumption $G$, which is determined as the residual in our benchmark economy, but is held constant across our policy experiments. The government's budget constraint is given by:

$$
\begin{aligned}
& \int\left\{\tau_{l}\left[\left(w z n-q^{e} \cdot e\right)+S \cdot \imath_{j \geq J^{r}}\right]+\tau_{k} r(a+b)+\tau_{c} c+q^{m} \iota_{j \geq J^{r}}\right\} d \Phi \\
= & \int\left[T+\left(S+\omega_{m} \cdot x\right) \cdot \iota_{j \geq J^{r}}\right] d \Phi+G,
\end{aligned}
$$

where $\Phi$ is the cross sectional distribution of population over state variables and $l_{j \geq J^{r}}$ is a variable (0 or 1) indicating whether an individual is is retired (has reached age $J^{r}$ ).

\subsection{Production Technology}

On the production side, we assume competitive firms operate a standard constant returns to scale technology. Aggregate output $Y$ is given by

$$
Y=F(K, L)=K^{\theta} L^{1-\theta}
$$


where $K$ and $L$ are aggregate capital and effective labor. Capital is assumed to depreciate at the rate $\delta$ each period.

\subsection{Competitive Equilibrium}

\subsubsection{Timeline}

At the beginning of each period, individuals observe their asset holdings $a$ determined in the previous period, a job offer that consists of a productivity draw $z$ and an indicator $e(0$ or 1) as to whether the job comes with EHI, and their health status $h$. That is, their beginning of period state is given by $s=(j, a, h, z, e)$. They then make a decision to accept or reject the job offer and whether or not to purchase a private individual insurance contract $\left(l_{I H I}\right)$ or early retiree health insurance $\left(l_{R H I}\right)$ before this period's medical shock $x$ is realized. After the insurance purchase and labor decisions are made, health status $h^{\prime}$ and medical expenditure $x$ are realized and then households make decisions on consumption $c$ and end of period asset holdings $a^{\prime}$.

\subsubsection{Individual's dynamic program}

Given prices and tax rates, the problem solved by an individual of age $j=1, \ldots, J^{r}-1$ can be written as follows:

$$
V(s)=\max _{n \in\{0, \bar{n}\}, \iota_{l H I}, \iota_{R H I}} \sum_{\left(h^{\prime}, x\right)} \pi_{j}^{x}\left(x \mid h^{\prime}\right) \pi_{j}^{h}\left(h^{\prime}, h\right)\left\{\max _{c, a^{\prime}} u(c, n)+\beta \rho_{j, h^{\prime}} \sum_{\left(z^{\prime}, e^{\prime}\right)} P_{\left(z^{\prime}, e^{\prime}\right) \mid(z, e)}^{h^{\prime}, j} V\left(s^{\prime}\right)\right\}
$$

subject to

$$
\begin{aligned}
& \left(1+\tau_{c}\right) c+a^{\prime}+q^{i}(j, h) i_{I H I}+q^{g} i_{R H I}=W+T \\
& W \equiv\left(1-\tau_{l}\right)\left(w z n-q^{e} * \imath_{E H I}\right)+\left(1+\left(1-\tau_{k}\right) r\right)(a+b)-(1-\hat{\omega}) x \\
& T=\max \left\{0,\left(1+\tau_{c}\right) \underline{c}-W\right\} \\
& \hat{\omega}= \begin{cases}\omega & \text { if } \imath_{E H I}=1, \imath_{R H I}=1, \text { or } \iota_{I H I}=1 \\
0 & \text { otherwise }\end{cases} \\
& \iota_{E H I}= \begin{cases}1 & \text { if } e=1 \text { and } n=\bar{n} \\
0 & \text { otherwise }\end{cases} \\
& \iota_{R H I} \in \begin{cases}\{0,1\} & \text { if } e=1, n=0 \text { and } J^{g} \leq j \leq J^{r}-1 \\
\{0\} & \text { otherwise }\end{cases} \\
& a^{\prime} \geq 0 ; c \geq 0 .
\end{aligned}
$$


Similarly, the problem of a retiree aged $j=J^{r}, \ldots, J$ is the following, where $h^{\prime}$ and $x$ are revealed before any decisions need to be made:

$$
V(j, a, h)=\max _{c, a^{\prime}}\left\{u(c, 0)+\beta \rho_{j, h^{\prime}} V\left(j+1, a^{\prime}, h^{\prime}\right) \mid h^{\prime}, x\right\}
$$

subject to

$$
\begin{aligned}
& \left(1+\tau_{c}\right) c+a^{\prime}=W+T \\
& W \equiv S+\left(1+\left(1-\tau_{k}\right) r\right)(a+b)-\left(1-\omega_{m}\right) x-q^{m} \\
& T=\max \left\{0,\left(1+\tau_{c}\right) \underline{c}-W\right\} \\
& a^{\prime} \geq 0 ; \quad c \geq 0 .
\end{aligned}
$$

\subsubsection{Equilibrium definition}

A competitive equilibrium consists of a set of individual decision rules $\left[n(s), \imath_{I H I}(s), \imath_{R H I}(s)\right.$, and $a^{\prime}\left(s, x, h^{\prime}\right)$, a set of factor demands [ $K$ and $\left.L\right]$, and a set of prices $\left[w, r, q^{i}(j, h), q^{e}, q^{g}\right.$, and $q^{m}$ ] such that

1. Given prices, the individual decision rules solve the households dynamic program.

2. Factor demands must satisfy

$$
\begin{aligned}
& w=(1-\theta)(K / L)^{\theta} \\
& r=\theta(L / K)^{(1-\theta)}-\delta
\end{aligned}
$$

3. Markets clear

$$
\begin{aligned}
& L=\int n(s) z d \Phi \\
& K=\int(a+b) d \Phi
\end{aligned}
$$

where

$$
b=\int a\left(1-\rho_{j-1, h}\right) d \Phi
$$




$$
\begin{aligned}
q^{i}(j, h) & =\psi \sum_{\left(h^{\prime}, x\right)} \pi_{j}^{x}\left(x \mid h^{\prime}\right) \pi_{j}^{h}\left(h^{\prime}, h\right) \omega x \\
q^{e} & =\int \sum_{\left(h^{\prime}, x\right)} \pi_{j}^{x}\left(x \mid h^{\prime}\right) \pi_{j}^{h}\left(h^{\prime}, h\right) \omega\left(\iota_{E H I}+\sigma_{g} \imath_{R H I}\right) x d \Phi \\
q^{g} & \left.=\int \sum_{\left(h^{\prime}, x\right)} \pi_{j}^{x}\left(x \mid h^{\prime}\right) \pi_{j}^{h}\left(h^{\prime}, h\right) \omega\left(1-\sigma_{g}\right) \imath_{R H I}\right) x d \Phi \\
q^{m} & =\left(1-\sigma_{m}\right) \int \sum_{\left(h^{\prime}, x\right)} \pi_{j}^{x}\left(x \mid h^{\prime}\right) \pi_{j}^{h}\left(h^{\prime}, h\right) \omega_{m}\left(\iota_{j \geq J^{r}}\right) x d \Phi
\end{aligned}
$$

where $l_{j \geq J^{r}}$ is an indicator that is equal to one if the individual is of Medicare eligible and zero otherwise.

\subsection{Policy Experiment - Medicare buy-in}

Let $J^{b}$ be the age at which an individual becomes eligible to participate in the Medicare buy-in program by paying a premium equal to $q^{b}$. We consider cases where this premium is and is not dependent on age. We also consider the possibility of introducing a government subsidy to overcome the adverse selection problem. In our quantitative experiments, we set $J^{b}$ and $J^{g}$ equal to each other.

If this program is available, the problem of an individual eligible for the buy-in, those of age $J^{b}$ to $J^{r}-1$, becomes:

$V(s)=\max _{n \in\{0, \bar{n}\}, \iota_{I H I}, \iota_{R H I}, \iota_{M B}} \sum_{\left(h^{\prime}, x\right)} \pi_{j}^{x}\left(x \mid h^{\prime}\right) \pi_{j}^{h}\left(h^{\prime}, h\right)\left\{\max _{c, a^{\prime}} u(c, n)+\beta \rho_{j, h^{\prime}} \sum_{\left(z^{\prime}, e^{\prime}\right)} P_{\left(z^{\prime}, e^{\prime}\right) \mid(z, e)}^{h^{\prime}, j} V\left(s^{\prime}\right)\right\}$ 
subject to

$$
\begin{aligned}
& \left(1+\tau_{c}\right) c+a^{\prime}+q^{i}(j, h) i_{I H I}+q^{g} i_{R H I}+q^{b}(j) \imath_{M B}=W+T \\
& W \equiv\left(1-\tau_{l}\right)\left(w z n-q^{e} * l_{E H I}\right)+\left(1+\left(1-\tau_{k}\right) r\right)(a+b)-(1-\hat{\omega}) x \\
& T=\max \left\{0,\left(1+\tau_{c}\right) \underline{c}-W\right\} \\
& \hat{\omega}= \begin{cases}\omega & \text { if } \imath_{E H I}=1, \imath_{R H I}=1, \imath_{M B}=1, \text { or } \iota_{I H I}=1 \\
0 & \text { otherwise }\end{cases} \\
& \iota_{E H I}= \begin{cases}1 & \text { if } e=1 \text { and } n=\bar{n} \\
0 & \text { otherwise }\end{cases} \\
& \iota_{R H I} \in \begin{cases}\{0,1\} & \text { if } e=1, n=0 \text { and } J^{g} \leq j \leq J^{r}-1 \\
\{0\} & \text { otherwise }\end{cases} \\
& a^{\prime} \geq 0 ; c \geq 0,
\end{aligned}
$$

where $t_{M B}$ is an indicator that takes a value of one if the agent qualifies for the Medicare buy-in and indeed buys it, and takes a value of zero otherwise.

In competitive equilibrium, if the Medicare buy-in program is subsidized at the rate $\sigma_{b}$, the equilibrium premium will be as follows:

$$
q^{b}(j)=\left(1-\sigma_{b}\right) \int \sum_{\left(h^{\prime}, x\right)} \pi_{j}^{x}\left(x \mid h^{\prime}\right) \pi_{j}^{h}\left(h^{\prime}, h\right) \omega_{b} \imath_{M B} \imath_{j} x d \Phi
$$

where $l_{j}$ is an indicator equal to one if the individual is age $j$ and zero otherwise. If the Medicare buy-in is not priced by age, the premium becomes

$$
q^{b}=\left(1-\sigma_{b}\right) \int \sum_{\left(h^{\prime}, x\right)} \pi_{j}^{x}\left(x \mid h^{\prime}\right) \pi_{j}^{h}\left(h^{\prime}, h\right) \omega_{b} \iota_{M B} x d \Phi
$$

\section{Calibration}

To calibrate the earning processes, health expenditure shocks and to obtain empirical estimates of health insurance coverage rates, we use income, health status, health expenditures and insurance status from the Medical Expenditure Panel Survey (MEPS). We use eight two-year panels from 1999/2000 up to 2006/2007. We focus only on heads of households, which we define to be the individual (male or female) with the highest income in a particular insurance eligibility unit. Attached to each of these household heads is a weight that can be used to make adjustments for the possibility that the MEPS sample of individuals may not reflect the distribution of individuals in the population as a whole. 


\subsection{Health Insurance}

The coverage rates for the various forms of insurance are constructed from MEPS data as follows. To be considered as having EHI in a given year, the respondent in the MEPS survey must have been employed and covered by some form of group insurance during the year. In particular, to be classified as "employed," the respondent must have answered that they were employed in at least two of the three interviews conducted in a given year. In order to be considered as covered by insurance, the respondent must declare that they are covered at least eight months of a given year. To be counted as having RHI, the respondent needs to be covered by some form of group insurance and not be employed. To be counted as being covered by IHI, the respondent would have been covered by private insurance (source unknown), nongroup insurance, or self-employment insurance.

We follow Attanasio, Kitao and Violante (2009) and set the reimbursement rate for private health insurance, $\omega$, equal to 0.7 , and the reimbursement rate for Medicare, $\omega_{m}$, equal to 0.5 . We set the markup for IHI, $\psi$, so that the IHI coverage rates predicted by our model match observed rates in MEPS data for individuals (household heads) aged 55 to 64 . The fraction of the total cost of Medicare paid by the government, $\sigma_{m}$, is set equal to 0.88 [see Kaiser Family Foundation (2010)]. The remaining cost is financed by the Medicare premium, $q^{m}$. Finally, we set the subsidy rate for early retirement insurance, $\sigma_{g}$, equal to 0.6 based on findings from the 2006 Kaiser/Hewitt Retiree Health Benefits Survey [see Kaiser Family Foundation (2006)].

The ages of eligibility for RHI and the Medicare buy-in, which are denoted by $J^{g}$ and $J^{b}$, are both set equal to 35 . This corresponds to age 55 in the data.

\subsection{Earnings and Employment Health Insurance}

We jointly calibrate earnings and access to EHI or RHI, which we take as being attached to an employment opportunity. We set the number of earnings states to $N=5$. In order to obtain values for these five grid points for $z$, we compute the average wage earnings from the whole sample in 2007 dollars, which turns out to be $\$ 34,958$. Next, we compute average earnings for the top $15 \%$ of earners, the next $20 \%, 30 \%, 20 \%$, and the bottom $15 \%$. Our earnings states are then computed as the ratio of these averages to the average of the whole sample:

$$
Z=\{0.0029,0.2667,0.6811,1.2011,2.4235\}
$$

Transition matrices are computed for five year age groups from 21 to 65 . Each individual in the MEPS database is interviewed in two adjacent years, so we can compute the proba- 
bility of moving from one earnings/EHI bin to another in one year, conditional on age and reported health status, by simply computing the weighted fraction of individuals who made that transition. In this way we construct the joint transition probabilities $P^{h^{\prime}, j}\left(z^{\prime}, e^{\prime} \mid z, e\right)$ of going from income bin $z$ with insurance status $e$ to income bin $z^{\prime}$ with $e^{\prime}{ }^{5}$ Hence, the joint Markov process is defined over $5 \times 2$ states with a transition matrix $P^{h^{\prime}, j}\left(z^{\prime}, e^{\prime} \mid z, e\right)$ of size $10 \times 10$. For each age group, we compute two transition matrices corresponding to good and bad health status.

Table 1 displays the joint transition matrices of age-group 51-55 for both $h^{\prime}=h_{g}$ and $h^{\prime}=h_{b}$ as an example. The other matrices can be obtained from the authors.

We found that a high earners are more likely to be offered EHI $(e=1)$, and that this state is persistent over time.

\subsection{Health Status and Health Expenditures}

The MEPS database is also used to calculate age dependent transition matrices for health status and the probability distribution of health expenditures conditional on health status. Each individual is interviewed three times in a given a year and we compute the average of the health status indicator $(1-5)$ that is provided by the individual's response to the question, "In general, compared to other people of your age, would you say that your health is excellent (1), very good (2), good (3), fair (4), or poor (5)?" If the average is greater than 3, we say $h=h_{b}$ and set $h=h_{g}$ otherwise. We can then construct age dependent transition matrices as described above for the earnings state. The transition matrices of the health status for different age groups, which are calculated using the same method as in the previous subsection, are reported in Table 2.

In order to capture the long-tail in the distribution of the health expenditures and a small probability of incurring very large and catastrophic expenditures, we use three expenditure states with uneven measures (average of top 5\%, next 35\% and bottom 60\%) for each age and health status. The distribution of health expenditures by age and health status is displayed in Table 3.

\footnotetext{
${ }^{5}$ Let the $X$ be the set of all 10 possible earnings/EHI states and let $G^{h^{\prime}}, j\left(x, x^{\prime}\right)$ be the group of households who move from state $x \in X$ to state $x^{\prime} \in X$. The gross flow from state $x$ to $x^{\prime}$ is given by $F^{h^{\prime}, j}\left(x, x^{\prime}\right)=\sum_{i \in G^{h^{\prime}, j}\left(x, x^{\prime}\right)} w_{i}$, where $w_{i}$ is the weight associated with individual $i$ in the MEPS sample. The transition probabilities can then be calculated from these flows, $P^{h^{\prime}, j}\left(x^{\prime} \mid x\right)=\frac{F^{h^{\prime}, j}\left(x, x^{\prime}\right)}{\sum_{y \in X} F^{h^{\prime}, j}(x, y)}$.
} 
Table 1: Joint transition matrices of earnings and EHI offer by age group 51-55

\begin{tabular}{|c|c|c|c|c|c|c|c|c|c|c|}
\hline $\begin{array}{c}\text { Age 51-55 } \\
\left(h^{\prime}=h_{g}\right)\end{array}$ & $\begin{array}{l}e^{\prime}=1 \\
z^{\prime}=z_{1}\end{array}$ & $\begin{array}{l}e^{\prime}=1 \\
z^{\prime}=z_{2}\end{array}$ & $\begin{array}{l}e^{\prime}=1 \\
z^{\prime}=z_{3}\end{array}$ & $\begin{array}{l}e^{\prime}=1 \\
z^{\prime}=z_{4}\end{array}$ & $\begin{array}{l}e^{\prime}=1 \\
z^{\prime}=z_{5}\end{array}$ & $\begin{array}{l}e^{\prime}=0 \\
z^{\prime}=z_{1}\end{array}$ & $\begin{array}{l}e^{\prime}=0 \\
z^{\prime}=z_{2}\end{array}$ & $\begin{array}{l}e^{\prime}=0 \\
z^{\prime}=z_{3}\end{array}$ & $\begin{array}{l}e^{\prime}=0 \\
z^{\prime}=z_{4}\end{array}$ & $\begin{array}{l}e^{\prime}=0 \\
z^{\prime}=z_{5}\end{array}$ \\
\hline$e=1 z=z_{1}$ & 0.446 & 0.028 & 0.103 & 0.147 & 0.052 & 0.091 & 0.008 & 0.107 & 0.019 & 0.000 \\
\hline$e=1 z=z_{2}$ & 0.000 & 0.243 & 0.356 & 0.086 & 0.081 & 0.022 & 0.076 & 0.115 & 0.021 & 0.000 \\
\hline$e=1 z=z_{3}$ & 0.006 & 0.057 & 0.569 & 0.221 & 0.068 & 0.004 & 0.026 & 0.035 & 0.009 & 0.005 \\
\hline$e=1 z=z_{4}$ & 0.006 & 0.016 & 0.147 & 0.575 & 0.222 & 0.001 & 0.007 & 0.012 & 0.013 & 0.002 \\
\hline$e=1 z=z_{5}$ & 0.003 & 0.008 & 0.037 & 0.143 & 0.779 & 0.002 & 0.002 & 0.001 & 0.012 & 0.015 \\
\hline$e=0 z=z_{1}$ & 0.000 & 0.019 & 0.005 & 0.000 & 0.015 & 0.712 & 0.188 & 0.046 & 0.015 & 0.000 \\
\hline$e=0 z=z_{2}$ & 0.000 & 0.039 & 0.067 & 0.008 & 0.008 & 0.091 & 0.465 & 0.256 & 0.025 & 0.043 \\
\hline$e=0 z=z_{3}$ & 0.002 & 0.017 & 0.081 & 0.045 & 0.005 & 0.039 & 0.157 & 0.469 & 0.130 & 0.054 \\
\hline$e=0 z=z_{4}$ & 0.000 & 0.018 & 0.044 & 0.110 & 0.037 & 0.020 & 0.056 & 0.252 & 0.242 & 0.220 \\
\hline$e=0 z=z_{5}$ & 0.000 & 0.000 & 0.012 & 0.037 & 0.087 & 0.010 & 0.076 & 0.074 & 0.216 & 0.488 \\
\hline $\begin{array}{c}\text { Age 51-55 } \\
\left(h^{\prime}=h_{b}\right)\end{array}$ & $\begin{array}{l}e^{\prime}=1 \\
z^{\prime}=z_{1}\end{array}$ & $\begin{array}{l}e^{\prime}=1 \\
z^{\prime}=z_{2}\end{array}$ & $\begin{array}{l}e^{\prime}=1 \\
z^{\prime}=z_{3}\end{array}$ & $\begin{array}{l}e^{\prime}=1 \\
z^{\prime}=z_{4}\end{array}$ & $\begin{array}{l}e^{\prime}=1 \\
z^{\prime}=z_{5}\end{array}$ & $\begin{array}{l}e^{\prime}=0 \\
z^{\prime}=z_{1}\end{array}$ & $\begin{array}{l}e^{\prime}=0 \\
z^{\prime}=z_{2}\end{array}$ & $\begin{array}{l}e^{\prime}=0 \\
z^{\prime}=z_{3}\end{array}$ & $\begin{array}{l}e^{\prime}=0 \\
z^{\prime}=z_{4}\end{array}$ & $\begin{array}{l}e^{\prime}=0 \\
z^{\prime}=z_{5}\end{array}$ \\
\hline$e=1 z=z_{1}$ & 0.614 & 0.087 & 0.038 & 0.069 & 0.070 & 0.123 & 0.000 & 0.000 & 0.000 & 0.000 \\
\hline$e=1 z=z_{2}$ & 0.056 & 0.372 & 0.313 & 0.010 & 0.020 & 0.109 & 0.061 & 0.059 & 0.000 & 0.000 \\
\hline$e=1 z=z_{3}$ & 0.046 & 0.067 & 0.528 & 0.188 & 0.038 & 0.024 & 0.034 & 0.076 & 0.000 & 0.000 \\
\hline$e=1 z=z_{4}$ & 0.023 & 0.002 & 0.230 & 0.537 & 0.172 & 0.006 & 0.000 & 0.000 & 0.010 & 0.020 \\
\hline$e=1 z=z_{5}$ & 0.000 & 0.012 & 0.060 & 0.199 & 0.720 & 0.004 & 0.005 & 0.000 & 0.000 & 0.000 \\
\hline$e=0 z=z_{1}$ & 0.007 & 0.001 & 0.008 & 0.000 & 0.008 & 0.871 & 0.095 & 0.005 & 0.006 & 0.000 \\
\hline$e=0 z=z_{2}$ & 0.000 & 0.043 & 0.050 & 0.004 & 0.000 & 0.194 & 0.535 & 0.131 & 0.031 & 0.012 \\
\hline$e=0 z=z_{3}$ & 0.000 & 0.055 & 0.116 & 0.037 & 0.000 & 0.072 & 0.194 & 0.451 & 0.076 & 0.000 \\
\hline$e=0 z=z_{4}$ & 0.000 & 0.092 & 0.028 & 0.192 & 0.202 & 0.000 & 0.144 & 0.157 & 0.186 & 0.000 \\
\hline$e=0 z=z_{5}$ & 0.000 & 0.000 & 0.000 & 0.000 & 0.000 & 0.000 & 0.052 & 0.500 & 0.272 & 0.176 \\
\hline
\end{tabular}


Table 2: Transition probabilities of health status by age group

\begin{tabular}{cccc}
\hline Age & & $h^{\prime}=h_{g}$ & $h^{\prime}=h_{b}$ \\
\hline $21-30$ & $h=h_{g}$ & 0.96 & 0.04 \\
& $h=h_{b}$ & 0.48 & 0.52 \\
\hline $31-40$ & $h=h_{g}$ & 0.96 & 0.04 \\
& $h=h_{b}$ & 0.38 & 0.62 \\
\hline $41-50$ & $h=h_{g}$ & 0.94 & 0.06 \\
& $h=h_{b}$ & 0.32 & 0.68 \\
\hline $51-60$ & $h=h_{g}$ & 0.93 & 0.07 \\
& $h=h_{b}$ & 0.28 & 0.72 \\
\hline $61-70$ & $h=h_{g}$ & 0.90 & 0.10 \\
& $h=h_{b}$ & 0.30 & 0.70 \\
\hline $71-80$ & $h=h_{g}$ & 0.88 & 0.12 \\
& $h=h_{b}$ & 0.31 & 0.69 \\
\hline $81-$ & $h=h_{g}$ & 0.87 & 0.13 \\
& $h=h_{b}$ & 0.34 & 0.66 \\
\hline
\end{tabular}

Table 3: Health expenditures from MEPS ( 2007 dollars)

\begin{tabular}{ccrrr}
\hline & & \multicolumn{3}{c}{ Medical expenditure } \\
\cline { 3 - 5 } Age & Health & Bottom 60\% & Next 35\% & Top 5\% \\
\hline $20-29$ & $h_{g}$ & 76.19 & 1520.49 & 12163.42 \\
& $h_{b}$ & 389.14 & 5027.02 & 33470.09 \\
\hline $30-39$ & $h_{g}$ & 136.80 & 1898.03 & 13644.96 \\
& $h_{b}$ & 621.60 & 7055.62 & 60358.85 \\
\hline $40-49$ & $h_{g}$ & 275.13 & 2769.24 & 19939.88 \\
& $h_{b}$ & 1055.28 & 9410.88 & 55337.89 \\
\hline $50-64$ & $h_{g}$ & 639.93 & 4630.72 & 29758.45 \\
& $h_{b}$ & 1947.97 & 13234.47 & 66826.10 \\
\hline $65-$ & $h_{g}$ & 1560.28 & 9703.30 & 49647.48 \\
& $h_{b}$ & 3402.35 & 19590.86 & 74479.44 \\
\hline
\end{tabular}


Table 4: Summary of parameters

\begin{tabular}{lccc}
\hline \hline Parameters & Notations & Values & Target/Note \\
\hline Discount Factor & $\beta$ & 0.967 & $K / Y$ ratio $=3$ \\
Utility Parameter & $\mu$ & 3 & Relative risk aversion 2.4 \\
$\begin{array}{l}\text { Depreciation Rate } \\
\text { Labor Parameter }\end{array}$ & $\delta$ & 0.08 & \\
Capital Income Share & $\phi$ & 0.72 & Employment rate of those age \\
IHI Premium Markup & $\theta$ & 0.36 & $55-64=71 \%$ (MEPS) \\
& $\psi$ & 1.092 & IHI coverage rate for age \\
RHI subsidy rate & & & $55-64=5.9 \%$ (MEPS) \\
Social Welfare & $\sigma_{g}$ & $60 \%$ & Kaiser Family Foundation (2006) \\
& $\underline{\mathrm{c}}$ & $14 \%$ of & Fraction with asset holdings $<$ (Kennickell, 2003) \\
Social security & $S$ & $45 \%$ of & \\
benefit & & avg earnings & \\
PHI reimbursement rate & $\omega$ & 0.70 & Attanasio et.al. (2008) \\
Medicare reimbursement rate & $\omega_{m}$ & 0.50 & Attanasio et.al. (2008) \\
Medicare subsidy rate & $\sigma_{m}$ & 0.88 & Kaiser Family Foundation (2010) \\
Consumption tax rate & $\tau_{c}$ & 0.05 & Mendoza et.al. (1994) \\
Capital tax rate & $\tau_{k}$ & 0.40 & Mendoza et.al. (1994) \\
Labor tax rate & $\tau_{l}$ & 0.35 & \\
\hline
\end{tabular}




\subsection{Demographics, Preference and Technology}

Following studies similar to ours, the utility discount factor $\beta$ is set so that the capital output ratio is equal to 3.0, the utility parameter $\mu$ is set equal to 3 , and $\phi$ is selected so that aggregate labor hours is equal to 0.3 . The above setting implies that the relative risk aversion coefficient is 2.4 , which is in the range of the estimates (between one and three) suggested in the empirical consumption literature (see Attanasio (1999), for a survey). The health dependent survival probabilities over the life cycle are taken from Attanasio, Kitao and Violante (2009) and Imrohoroglu and Kitao (2009).

The capital income share parameter $(\theta)$ in the production function is set equal to 0.36 and the depreciation rate of capital $(\delta)$ is set equal to 0.08 .

\subsection{Social Security, Consumption Guarantee and Government taxation}

The social security payment is set equal to $45 \%$ of the average labor income of working age adults. The minimum consumption floor is calibrated so that the proportion of individuals with asset levels lower than $\$ 1,000$ is equal to $13 \%$. This percentage is the average across the individual years reported in Table 4 of Kennickell (2003).

The consumption tax rate $\left(\tau_{c}\right)$ is set equal to $5 \%$, the capital income tax rate $\left(\tau_{k}\right)$ is $40 \%$, and the labor income lax rate $\left(\tau_{l}\right)$ is $35 \%$. These are based on measurements from Mendoza et.al. (1994). The labor tax rate is higher than the one reported in that paper since ours incorporates both the labor income tax and the payroll taxes that finance social security and Medicare.

Our calibration is summarized in Table 4.

\section{Quantitative Analysis}

We first describe the properties of the benchmark economy that characterizes some features of the current US insurance market. We will then compare this economy to one with an optional Medicare buy-in program.

\subsection{Benchmark economy}

Table 5 presents some summary statistics from our benchmark economy, including health insurance coverage rates, aggregate labor supply, capital-output ratio and the equilibrium interest rate. 
Table 5: Benchmark properties

\begin{tabular}{cccccc}
\hline $\begin{array}{c}\text { PHI coverage } \\
\text { 21-64 }\end{array}$ & $\begin{array}{c}\text { PHI coverage } \\
55-64\end{array}$ & $\begin{array}{c}\text { Labor } \\
\text { hours }\end{array}$ & $\begin{array}{c}\text { Employment Rate } \\
(\text { age }<65)\end{array}$ & $\begin{array}{c}\text { Capital-output } \\
\text { ratio }\end{array}$ & $r$ \\
\hline $73 \%$ & $70 \%$ & 0.32 & $87 \%$ & 3.0 & $4 \%$ \\
\hline
\end{tabular}

Note: PHI=EHI+RHI+IHI.

Figure 1: EHI+RHI and IHI coverage rates (Benchmark)

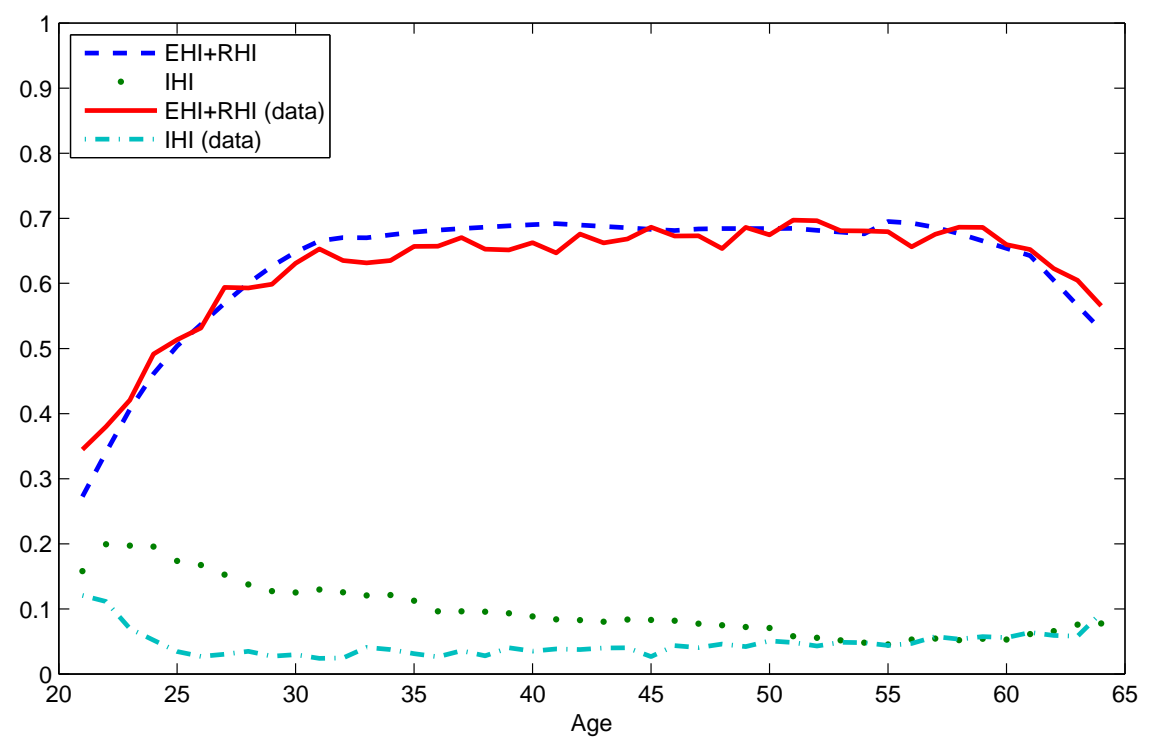


Figure 2: EHI and RHI coverage rates (Benchmark)

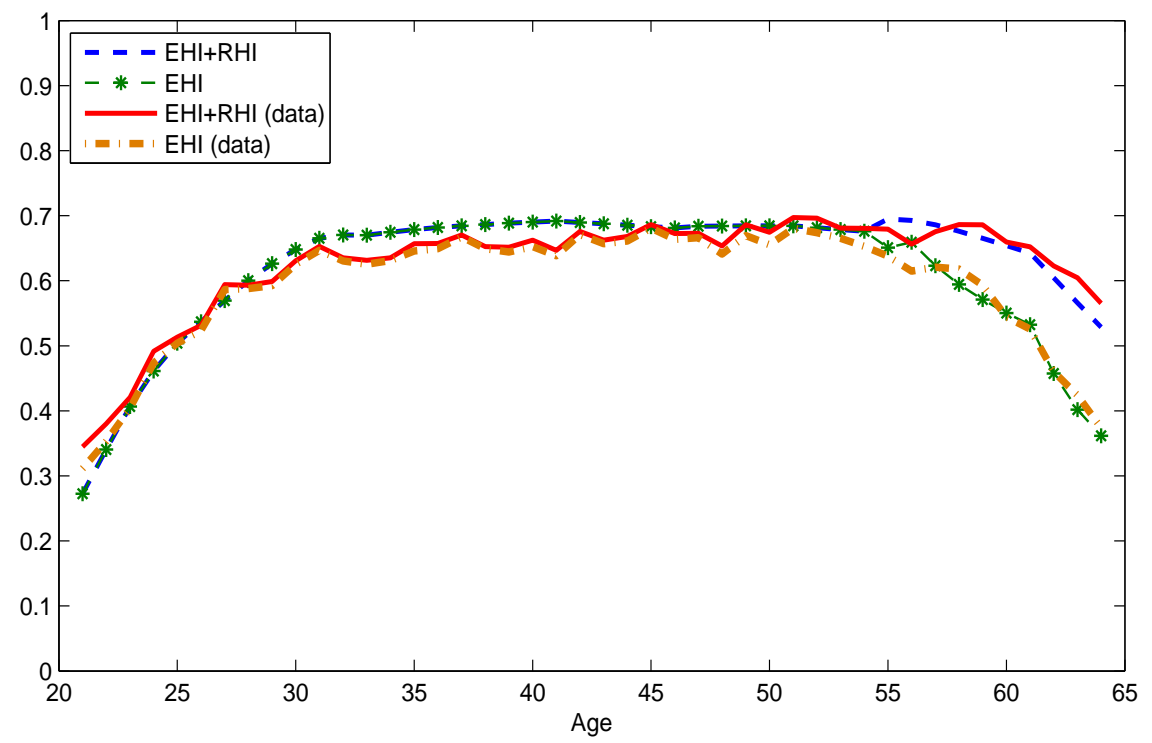

Figure 3: Employment Rate by Age (Benchmark)

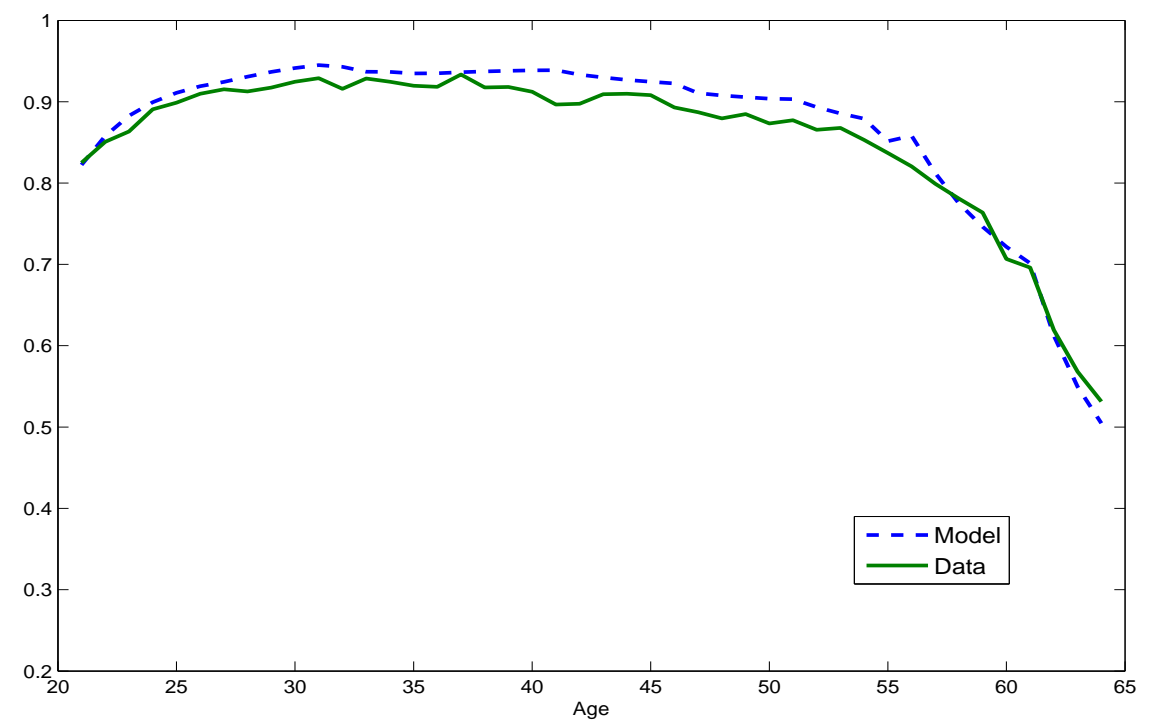


Figure 4: Counterfactual: Employment Rate by Age with no EHI

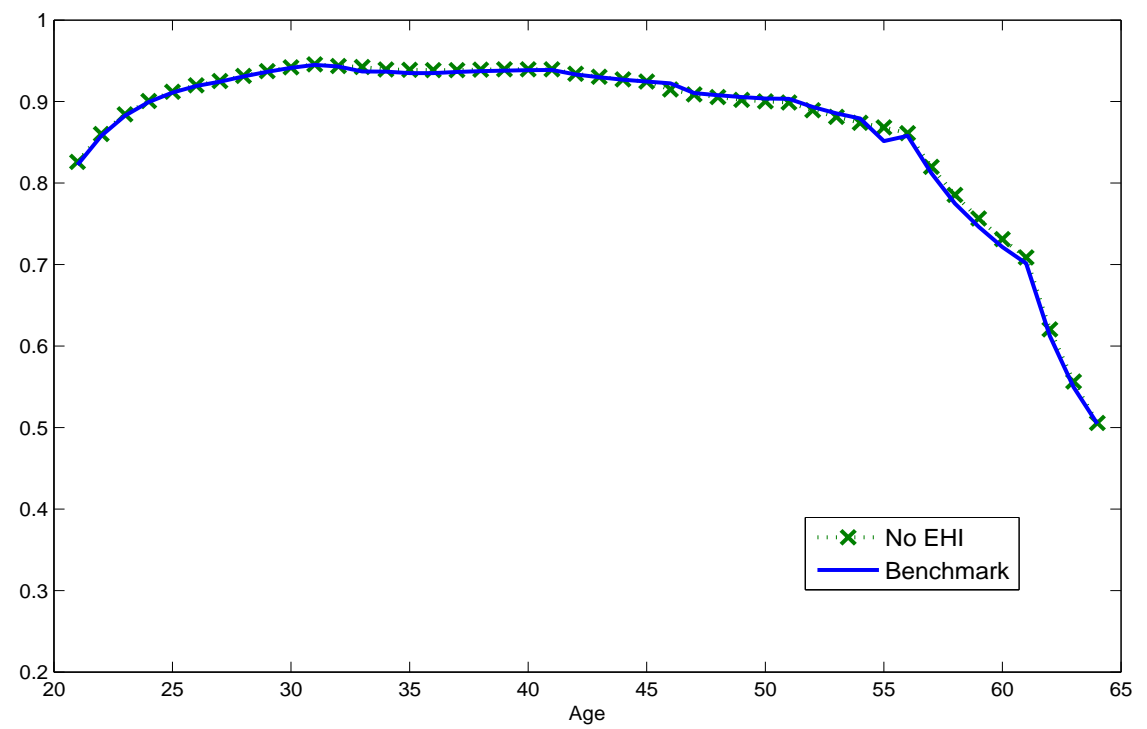

Figure 1 shows health insurance coverage rates by age for the model economy and from MEPS data. In particular, we show EHI (employer provided health insurance) plus RHI (retiree health insurance) coverage rates as well as IHI (individual private health insurance). Recall that we calibrated the parameter $\psi$ in order to match IHI coverage rates for those aged 55-64, and our success on this dimension can be seen in the figure. Our model, however, predicts that more people aged 21-50 should purchase IHI than observed in the data. The EHI+RHI coverage rates in the model are similar to those in the data for all ages, and this is due to our estimation of the joint transition matrices of earnings and EHI offers from MEPS data. Figure 2 shows EHI+RHI and EHI separately.

Next, Figure 3 shows that employment rates by age predicted by our model are very similar to those computed from MEPS data.

We also performed a counterfactual experiment where EHI and RHI are removed as options in the benchmark economy. The purpose is to determine whether the age profile of employment is affected by this change. As can be seen in Figure 4, employment rates are essentially identical in this counterfactual case as in the benchmark. Hence, there appears to be no sense in which people are "locked in" to employment in order to maintain their EHI 
coverage. ${ }^{6}$ This experiment is meant to illuminate why, once we add the Medicare Buy-in option, we find little or no effect on employment rates at any age.

The first block of lines in Table 6 reports the percentage of individuals aged 55-64 without health insurance and the equilibrium labor income tax rate for the benchmark economy. In addition, we report the same statistics for the benchmark economy without EHI or RHI. If employer provided group insurance options are removed, the percentage of uninsured increases from about 30 percent to 71 percent. Individuals still could choose to purchase IHI, which is not tax deductable in our economy, but most do not. The tax rate, on the other hand, is reduced from $35 \%$ to $34 \%$ due to the broadening of the tax base that would result from eliminating EHI and the tax free income that EHI represents.

\subsection{Policy Reform - Medicare Buy-in}

In this section we consider how insurance coverage is affected by introducing a Medicare Buy-in optional for individuals aged 55-64. As shown in the first line of Table 6, under the benchmark calibration, 30 percent of individuals aged 55-64 have no health insurance and the tax rate on labor income, $\tau_{n}$, is 35 percent.

When a Medicare Buy-in program is introduced, with one price for all and fully funded by program participants, adverse selection eliminates the market for this form of insurance. That is, healthy individuals would rather purchase IHI or self-insure, and their refusal to participate drives up the equilibrium price for others. In the end, there doesn't exist a price at which this program would have participants and at the same time be fully funded. This result would hold even if there is an insurance mandate as long as IHI is available as an alternative to the Medicare Buy-in.

This finding led us to consider the implications of offering the Medicare buy-in at a discounted price funded by a government subsidy. In Table 6 we show results for various subsidy levels in the second block of rows in the table. As the subsidy percentage is increased, the fraction of those aged 55-64 without health insurance falls. No matter how large the subsidy, some individuals will still not purchase health insurance because they are effectively being insured through the means tested social insurance program. In fact, the reduction in uninsured is relatively small for any subsidy level above 30 percent. At this

\footnotetext{
${ }^{6}$ This is consistent with empirical findings in Dey and Flinn (2005) and Gilleskie and Lutz (2002), although the data studied in these papers include only relatively young workers and does not include our target demographic of individuals aged 55-64. On the other hand, French and Jones (2011) find that if the Medicare eligibility age was raised from 65 to 67 , individuals would delay retirement on average by 27 days. Hence, their findings indicate that group health insurance availability does impact the labor participation decision to a small extent.
} 
Table 6: Insurance coverage (age 55-64) and tax burden

\begin{tabular}{lccccc}
\hline Policy Reform & $\begin{array}{c}\text { Percent without } \\
\text { Insurance }\end{array}$ & $\begin{array}{c}\text { MB coverage } \\
\text { w/ no EHI offer }\end{array}$ & $\begin{array}{c}\text { MB tax } \\
\text { rate }\left(\tau_{M B}\right)\end{array}$ & $\begin{array}{c}\text { Labor tax } \\
\text { rate }\left(\tau_{n}\right)\end{array}$ & $\tau_{M B}+\tau_{n}$ \\
\hline Benchmark & $29.89 \%$ & - & - & $35.00 \%$ & $35.00 \%$ \\
Benchmark w/ no EHI/RHI & $70.89 \%$ & - & - & $34.01 \%$ & $34.01 \%$ \\
\hline MB (20\% Subsidy) & $26.29 \%$ & $15.10 \%$ & $0.03 \%$ & $35.01 \%$ & $35.04 \%$ \\
MB (29\% Subsidy) & $5.63 \%$ & $85.83 \%$ & $0.15 \%$ & $35.01 \%$ & $35.16 \%$ \\
MB (30\% Subsidy) & $4.50 \%$ & $89.05 \%$ & $0.16 \%$ & $35.02 \%$ & $35.18 \%$ \\
MB (50\% Subsidy) & $4.27 \%$ & $89.70 \%$ & $0.26 \%$ & $35.03 \%$ & $35.29 \%$ \\
\hline MB PA (15\% Subsidy) & $17.96 \%$ & $44.09 \%$ & $0.04 \%$ & $35.01 \%$ & $35.05 \%$ \\
MB PA (17\% Subsidy) & $4.98 \%$ & $87.68 \%$ & $0.09 \%$ & $35.01 \%$ & $35.10 \%$ \\
MB PA (20\% Subsidy) & $4.83 \%$ & $88.10 \%$ & $0.10 \%$ & $35.01 \%$ & $35.11 \%$ \\
MB PA (30\% Subsidy) & $4.47 \%$ & $89.13 \%$ & $0.16 \%$ & $35.02 \%$ & $35.18 \%$ \\
MB PA (50\% Subsidy) & $4.20 \%$ & $89.86 \%$ & $0.26 \%$ & $35.03 \%$ & $35.29 \%$ \\
\hline MB w/ no RHI (30\% Subsidy) & $4.54 \%$ & $89.01 \%$ & $0.20 \%$ & $34.87 \%$ & $35.07 \%$ \\
MB w/ no EHI/RHI for 55-64 & $4.50 \%$ & $95.50 \%$ & $0.45 \%$ & $34.58 \%$ & $35.03 \%$ \\
(30\% Subsidy) & $5.09 \%$ & $87.72 \%$ & $0.11 \%$ & $34.92 \%$ & $35.03 \%$ \\
MB PA w/ no RHI (17\% Subsidy) & & & & & $34.57 \%$ \\
MB PA w/ no EHI/RHI & $5.04 \%$ & $94.96 \%$ & $0.26 \%$ & $34.82 \%$ \\
for 55-64 (17\% Subsidy) & & & & & \\
\hline MB - Medicare Buy-in with one price for all participants. & & & &
\end{tabular}


Table 7: Characteristics of Individuals Age 55-64

(all numbers are percentages)

\begin{tabular}{lccc}
\hline & Benchmark & $\begin{array}{c}\text { MB } \\
\text { (30\% subsidy) }\end{array}$ & $\begin{array}{c}\text { MB PA } \\
\text { (17\% subsidy) }\end{array}$ \\
\hline Percent with no health insurance & 29.89 & 4.50 & 4.98 \\
Percent qualifying for social insurance & 3.67 & 3.55 & 3.57 \\
\% of uninsured qualifying for social insurance & 12.22 & 74.99 & 69.47 \\
\% of uninsured in poor health & 19.89 & 22.57 & 20.54 \\
Employment rate of uninsured & 43.32 & 3.95 & 6.90 \\
Earnings of uninsured/earnings of insured & 32.47 & 1.03 & 3.04 \\
Assets of uninsured/assets of insured & 50.16 & 0.86 & 1.29 \\
\hline
\end{tabular}

MB - Medicare Buy-in with one price for all participants.

MB PA - Medicare Buy-in with pricing by age.

level, the total tax on labor income needed to fund all government spending $\left(\tau_{n}+\tau_{M B}\right)$ is 35.18 percent. In addition, this tax rate can be decomposed into the tax rate needed to fund the Medicare buy-in subsidy ( $\tau_{M B}=0.16 \%$ ) and the tax rate needed to fund the rest of the government budget, which is $\tau_{n}=35.02 \%$.

Next, we consider the implications of price discriminating by age, as is done with many Medicare supplemental insurance programs offered in the U.S. We find that the adverse selection problem continues to eliminate a market for this form of insurance if the program is not subsidized. However, while a 30 percent subsidy was required to achieve 95 percent health insurance coverage among those aged 55-64,the same can be achieved with a 17 percent subsidy when there price discrimination by age. This can be seen in the third block of rows in Table 6. The total tax on labor income needed to fund all government programs is 35.1 percent, which is only tiny increase above the benchmark tax rate and is slightly less than the tax rate for the 30 percent subsidy case when price doesn't differ by age.

It seems reasonable to anticipate that if a subsidized Medicare buy-in were available, employer provided health insurance might disappear as an option for those who qualify for the buy-in program. This possibility motivated us to consider additional experiments assuming a subsidized Medicare buy-in program in which either RHI or both EHI and RHI are eliminated for those aged 55-64. In particular, we do this in world with a subsidized Medicare Buy-in (30 percent subsidy) when everyone pays the same price and in a world where there is price discrimination by age and the subsidy is 17 percent. As can be seen in the last block of rows in Table 6, the percentage of individuals of age 55-64 without in- 
surance is not much affected by eliminating these employer sponsored insurance programs if the buy-in option is available. ${ }^{7}$ Since more people would now take the buy-in option, the MB tax rate would be higher than in the corresponding case where EHI and RHI exist. However, given that a hundred percent of labor income would now be taxable since the tax deductability of EHI is no longer relevant, the total tax on labor income actually goes down relative to the corresponding case with EHI and RHI case. Even in the case where only RHI is eliminated, in which case the impact on tax deductability is less important, the total tax rate falls. This is because, as reported in Table 8, individuals are more likely to continue working if they do not have the RHI option available. This also has the implication that fewer people end up qualifying for social insurance.

In Table 7 we highlight some characteristics of those aged 55-64, particularly those without any health insurance. The main takeaway from this table is that, if a Medicare buy-in is available, the uninsured tend to be extremely poor relative to those with insurance and are very likely to qualify for social insurance. This is not the case in the benchmark economy. For example, the third row of this table shows that $75 \%$ of those without insurance when a subsidized Medicare buy-in is offered (the one price for all case) qualify for welfare. In the benchmark, only $12.22 \%$ of the uninsured qualify for social insurance.

Figures 5 and 6 show health insurance coverage rates by age for the subsidized Medicare buy-in cases compared with those for the benchmark economy. The introduction of the Medicare buy-in has essentially no effect on the coverage rates for individuals below age 55 and no effect on EHI coverage rates at any age. The Medicare buy-in completely eliminates demand for IHI among those aged 55-64. In addition, we find that availability of a subsidized Medicare buy-in has very little effect on employment rates at any age. That is, the employment rate by age looks the same as shown in Figure 3.

\subsection{Steady State Welfare}

The welfare benefit or cost of living in an economy with an alternative policy relative to living in the benchmark economy is measured by the consumption-equivalent variation (CEV). That is, we calculate the percentage change in consumption each period in the benchmark economy required to make an individual of age $i=1$ as well off in terms of expected life-

\footnotetext{
${ }^{7}$ On the other hand, as shown in the second line of Table 6 , if these options were eliminated and IHI was the only insurance available, the percentage of uninsured would be much larger.
} 
Figure 5: Health insurance coverage rates (MB 30\% Subsidy vs. Benchmark)

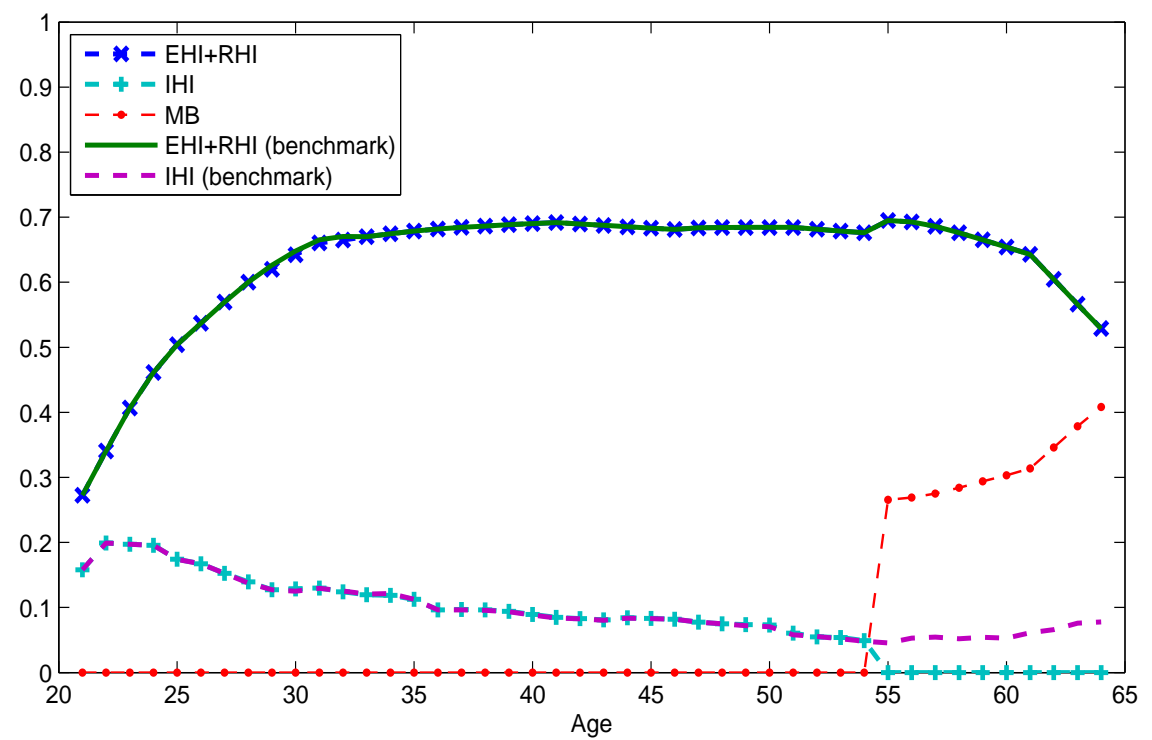

Figure 6: Health insurance coverage rates (MB PA 17\% Subsidy vs. Benchmark)

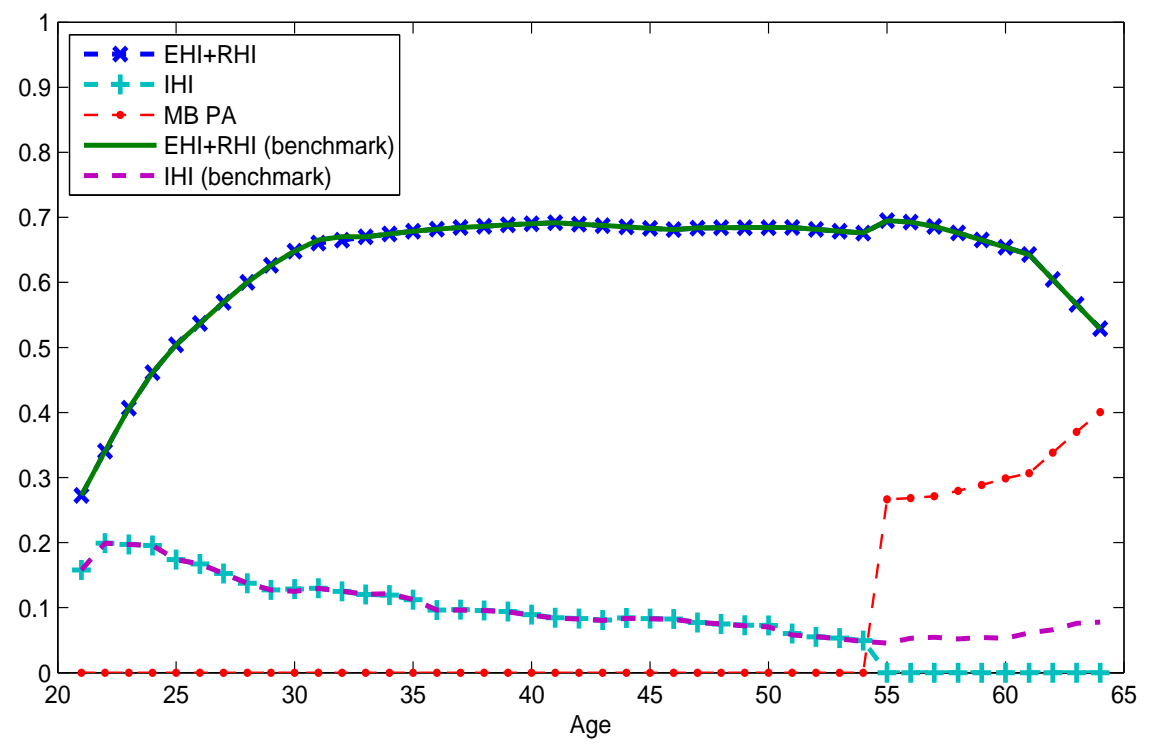


Table 8: Policy Reforms

(all numbers are percentages)

\begin{tabular}{lccc}
\hline & $\begin{array}{c}\text { Employment } \\
\text { Rate (21-64) }\end{array}$ & $\begin{array}{c}\text { \% qualifying for } \\
\text { social insurance }\end{array}$ & $\tau_{M B}+\tau_{n}$ \\
\hline Benchmark & 87.4 & 2.90 & 35.00 \\
MB (30\% subsidy) & 87.3 & 2.93 & 35.18 \\
MB PA (17\% subsidy) & 87.3 & 2.90 & 35.10 \\
MB w/ no RHI (30\% subsidy) & 87.8 & 2.84 & 35.07 \\
MB w/ no EHI/RHI for 55-64 & 87.7 & 2.81 & 35.03 \\
(30\% subsidy) & & & \\
MB PA w/ no RHI (17\% subsidy) & 87.8 & 2.86 & 35.03 \\
MB PA w/ no EHI/RHI for 55-64 & 87.7 & 2.81 & 34.82 \\
(17\% subsidy) & & & \\
\hline
\end{tabular}

time utility as someone of the same age in the alternative economy being considered. ${ }^{8}$

Table 9 compares welfare across the different cases studied. The subsidized Medicare buy-in policies reduce welfare compared with the benchmark due to the fact that taxes are raised on those younger than 55. On the other hand, if the introduction of a subsidized Medicare buy-in is accompanied with the elimination of EHI and RHI for those aged 5564, or if only RHI is eliminated, welfare is increased relative to the benchmark. The highest welfare among the cases considered in this table (including the benchmark) is the one with a subsidized Medicare Buy-in with price discrimination according to age (MB PA) and no

\footnotetext{
${ }^{8}$ We calculate the CEV for new-born agents who all have zero initial assets by assumption. This is defined by $\zeta$ in the following equation:

$$
\begin{aligned}
& \int E\left[\sum_{i=1}^{J} \beta^{i-1}\left(\prod_{t=1}^{i-1} \rho_{t, h}\right) u\left(c_{i}^{\text {alt }}, n_{i}^{\text {alt }}\right)\right] d \Phi^{\text {alt }}(s \mid j=1) \\
= & \int E\left[\sum_{i=1}^{J} \beta^{i-1}\left(\prod_{t=1}^{i-1} \rho_{t, h}\right) u\left((1+\zeta) c_{i}^{\text {bench }}, n_{i}^{\text {bench }}\right)\right] d \Phi^{\text {bench }}(s \mid j=1),
\end{aligned}
$$

where $c_{j}^{\text {alt }}, c_{j}^{\text {bench }}, n_{j}^{\text {alt }}$ and $n_{j}^{\text {bench }}$ are the optimal consumption and labor allocations for an age $j$ individual under the alternative and benchmark policies. In addition, $\Phi^{\text {alt }}(s \mid j=1)$ and $\Phi^{\text {bench }}(s \mid j=1)$ are the corresponding cross-sectional distribution of the population conditioned on being in the first period of life (recall that members of this cohort differ according to their draw of $h, z$, and $e$ ). Given the functional form of the utility function, the $\mathrm{CEV}, \zeta$, is given by

$$
\zeta=\left(\frac{\int V^{\text {alt }}(s) d \Phi^{\text {alt }}(s \mid j=1)}{\int V^{\text {bench }}(s) d \Phi^{\text {bench }}(s \mid j=1)}\right)^{1 /[\phi(1-\mu)]}-1,
$$

where $V^{\text {alt }}$ and $V^{\text {bench }}$ are the value functions for alternative and benchmark economies.
} 
Table 9: Welfare comparison (CEV from Benchmark*)

\begin{tabular}{cccc}
\hline $\begin{array}{c}\text { MB } \\
\text { (30\% subsidy) }\end{array}$ & $\begin{array}{c}\text { MB PA } \\
(17 \% \text { subsidy) }\end{array}$ & $\begin{array}{c}\text { MB w/ no E/RHI } \\
\text { for age 55-64 } \\
\text { (30\% subsidy) }\end{array}$ & $\begin{array}{c}\text { MB PA w/ no E/RHI } \\
\text { for age 55-64 } \\
\text { (17\% subsidy) }\end{array}$ \\
\hline$-0.19 \%$ & $-0.11 \%$ & $0.53 \%^{* *}$ & $0.76 \%$ \\
\hline
\end{tabular}

* CEV based on expected welfare at the beginning of life.

** If RHI is eliminated but EHI is still available for those 55-64, the CEV equals $0.18 \%$

EHI or RHI. This case has the lowest overall tax rate while providing insurance to a similar fraction of the population as the other cases.

Figure 7 shows the same welfare measure computed for individuals by age. That is, the welfare benefit to an individual of a particular age is the percentage increase in consumption each period from that age forward in the benchmark economy needed to make average expected lifetime utility equal to that in the alternative economy. ${ }^{9}$ Figure 7 shows that all working age individuals 36 and above would prefer living in the subsidized Medicare buyin economy rather than the benchmark economy when everyone pays the same price to participate in the program. The same is true for individuals 34 and above if the subsidized buy-in program is priced by age.

Figure 7 also shows the CEV by age for the subsidized Medicare buy-in program if EHI and RHI are eliminated for those of age 55-64 when the subsidized buy-in program is available. In these cases, the CEV is positive at all ages, which implies that all individuals prefer living in these economies relative to the benchmark. Younger individuals strongly prefer these cases because of the lower labor income tax rate. On the other hand, older individuals are relatively indifferent between the cases where EHI and RHI are eliminated versus the corresponding case where these programs remain since they put value on having EHI and RHI as options although they too benefit from the lower tax rate.

\footnotetext{
${ }^{9}$ The CEV for age $j=m$ is computed as follows:$$
C E V=\left(\frac{\int V^{\text {alt }}(s) d \Phi^{\text {alt }}(s \mid j=m)}{\int V^{\text {bench }}(s) d \Phi^{\text {bench }}(s \mid j=m)}\right)^{1 /[\phi(1-\mu)]}-1 .
$$ 
Figure 7: Steady State Welfare (CEV by age)

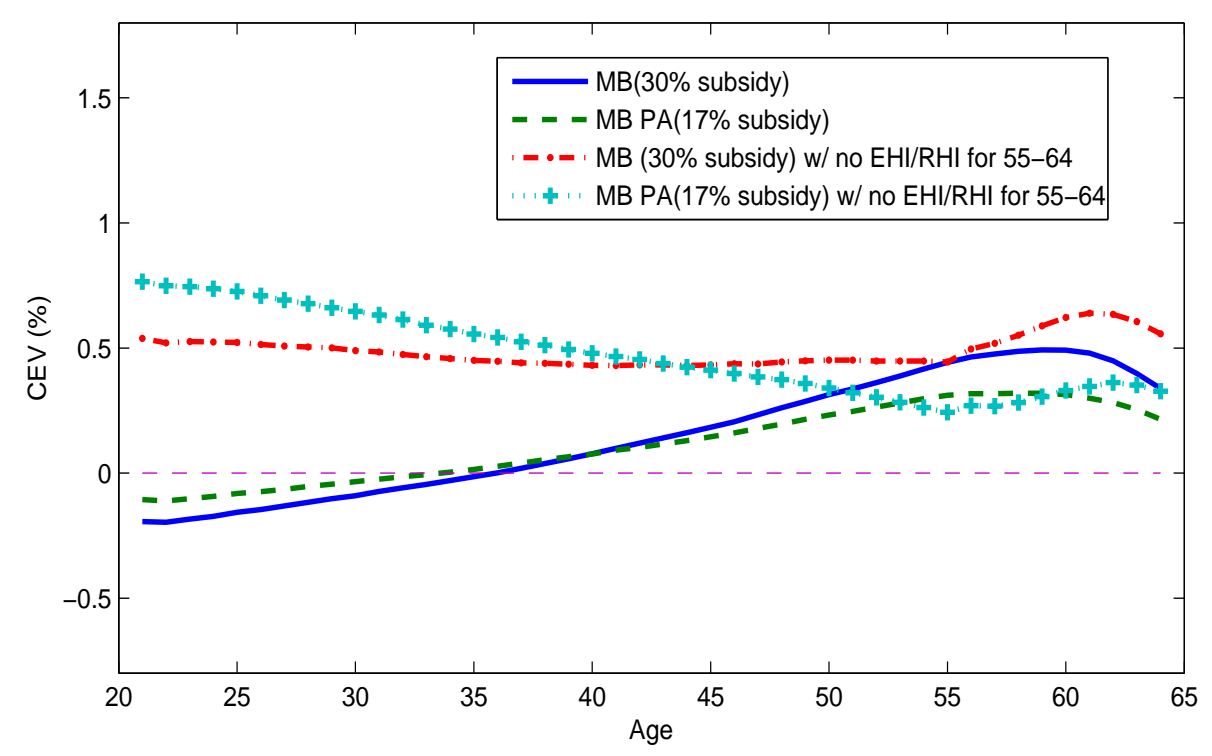

\section{Conclusion}

In this paper we have studied the impact of introducing an optional Medicare buy-in program for individuals aged 55-64 to an life cycle economy calibrated to features of the U.S. economy. We find that unless this program is subsidized by the government, an equilibrium with an active market for the Medicare buy-in will not exist due to adverse selection. Healthy individuals will prefer to purchase individual health insurance policies, or to selfinsure, instead of being pooled with less healthy individuals.

If the Medicare buy-in is subsidized, we find that it is possible to bring the number of individuals aged 55-64 without insurance to below 5 percent without incurring large tax increases to finance the program. In particular, a 30 percent subsidy brings the fraction uninsured down from 30 percent in the benchmark to 4.5 percent. In addition, due to the general equilibrium effects of introducing this policy, labor taxes only need to be raised a small amount relative to our benchmark economy. If the the Medicare buy-in is priced differently depending on an individual's age, a 17 percent subsidy is sufficient to bring the fraction uninsured below 5 percent. In addition, those of age 36 or higher (34 if there is pricing by age) would prefer to live in a world with a subsidized Medicare buy-in program than in the benchmark economy without this program. However, among all the cases we have 
considered, the highest steady state welfare is enjoyed in an economy in which employer provided health insurance is eliminated when the subsidized Medicare buy-in program is available.

Given the findings of this paper, in future work it would be interesting to compare the welfare and other implications of this program with those of the ACA. In particular, how does the subsidy used to implement the Medicare buy-in program in this paper compare with imposing a mandate that requires individuals to purchase group insurance as in the ACA? This research would contribute to the debate concerning the ACA and whether or not it would be desirable to repeal the ACA in favor of a Medicare buy-in or similar program.

\section{References}

Aiyagari, S. Rao (1994). "Uninsured Idiosyncratic Risk and Aggregate Saving," Quarterly Journal of Economics 109(3), 659-684.

Attanasio, O. (1999). Consumption. In: Taylor, J.B., Woodford, M. (Eds.), Handbook of Macroeconomics 1B. Elsevier, Amsterdam, 741-812.

Attanasio, O., S. Kitao, and G. Violante (2010). "Financing Medicare: A General Equilibrium Analysis." In J. B. Shoven (ed.), Demography and the Economy, NBER, University of Chicago Press, 333-366.

Auerbach, Alan J. and Laurence J. Kotlikoff (1987). Dynamic Fiscal Policy, Cambridge University Press.

Berenson, Robert, John Holahan and Stephen Zuckerman (2013). "Can Medicare be Preserved while Reducing the Deficit?" Timely Analysis of Immediate Health Policy Issues, Urban Institute, Robert Wood Johnson Foundation.

Bowles, Erskine and Alan Simpson (2013). "A Bipartisan Path Forward to Securing America's Future: Summary and Highlights." Moment of Truth Project, Washington DC.

Dey, Matthew S. and Christopher J. Flinn (2005). "An Equilibrium Model of Health Insurance Provision and Wage Determination.” Econometrica 73(2), 571-627.

French, Eric and John Bailey Jones (2011). "The Effects of Health Insurance and SelfInsurance on Retirement Behavior." Econometrica 79(3), 693-732.

Gilleskie, Donna B. and Byron F. Lutz (2002). "The Impact of Employer-Provided Health Insurance on Dynamic Employment Transitions." Journal of Human Resources 37(1) 129-162.

Heathcote, Jonathan, Kjetil Storesletten and Giovanni L. Violante (2008). "Insurance and Opportunities: A Welfare Analysis of Labor Market Risk." Journal of Monetary Eco- 
nomics 55, 501-525.

Hitt, Greg and Janet Adamy (2009). "Senate Turns to Medicare, Medicaid." Wall Street Journal, December 8, 2009.

Hubbard, R. G., J. Skinner and S. P. Zeldes (1995). "Precautionary saving and social insurance." Journal of Political Economy 103, 360-399.

Huggett, Mark (1993). "The Risk Free Rate in Heterogeneous-Agent, Incomplete-Insurance Economies." Journal of Economic Dynamics and Control 17, 953-969.

Imrohoroglu, Ayse (1989). "Cost of Business Cycles with Indivisibilities and Liquidity Constraints." Journal of Political Economy 97(6), 1364-1383.

Jacobson, Gretchen, Karyn Schwartz and Tricia Neuman (2009). "Health Insurance Coverage for Older Adults: Implications of a Medicare Buy-In.” Focus on Health Reform, The Henry J. Kaiser Family Foundation.

Jeske, Karsten and Sagiri Kitao (2009). "U.S. tax policy and health insurance demand: Can a regressive policy improve welfare?” Journal of Monetary Economics 56, 210-221.

Kaiser Family Foundation (2006). "Retiree Health Benefits Examined: Findings from the Kaiser/Hewitt 2006 Survey on Retiree Health Benefits." http://kff.org/health-costs/report/retireehealth-benefits-examined-findings-from-the/.

Kaiser Family Foundation (2010). "Medicare: A Primer.” http://kff.org/medicare/issuebrief/medicare-a-primer/.

Kennickell, A.B. (2003). "A rolling tide: changes in the distribution of wealth in the U.S.,1989 - 2001.” FEDS Working Paper No. 2003-24, Federal Reserve Board.

Mendoza, Enrique G., Assaf Razin and Linda L. Tesar (1994). "Effective Tax Rates in Macroeconomics: Cross-country Estimates of Tax Rates on Factor Incomes and Consumption.” Journal of Monetary Economics 34(3), 297-323.

Pashchenko, Svetlana and Ponpoje Porapakkarm (2013). "Quantitative Analysis of Health Insurance Reform: Separating Regulation from Redistribution." Review of Economic Dynamics 16, 383-404. forthcoming.

Smolka, Gerry and Sarah Thomas (2009). "A Medicare Buy-in Program.” Insight on the Issues I29, AARP Public Policy Institute. 